\title{
Erratum to: Impact of assimilating IASI radiance observations on forecasts of two tropical cyclones
}

\author{
Dongmei Xu $\cdot$ Zhiquan Liu $\cdot$ Xiang-Yu Huang •
} Jinzhong Min · Hongli Wang

Published online: 1 November 2013

(C) Springer-Verlag Wien 2013

Erratum to: Meteorol Atmos Phys (2013) 122:1-18

DOI 10.1007/s00703-013-0276-2

The authors would like to correct errors in the original publication as detailed below.

The correct version of the author's affiliation list is given here.

The online version of the original article can be found under doi:10.1007/s00703-013-0276-2.

D. Xu $\cdot$ J. Min

Nanjing University of Information Science and Technology

(NUIST), Nanjing 210044, China

D. Xu $\cdot$ Z. Liu $\cdot$ X.-Y. Huang $(\bowtie) \cdot$ H. Wang

National Center for Atmospheric Research, 3450 Mitchell LN,

Boulder, CO 80301, USA

e-mail: huangx@ucar.edu 